\title{
A condicionalidade de educação dos programas de transferência de renda: uma análise crítica do programa Bolsa Família
}

\author{
Bruna Cristina Neves Carnelossi* \\ Maria Eliza Mattosinho Bernardes**
}

\begin{abstract}
Resumo
O presente artigo analisa a relação de dependência entre educação e transferência de renda objetivada no Programa Bolsa Família, sobretudo entre sua proposta central de redução da pobreza e a contrapartida exigida na área da educação. A tese da eficácia de tal condicionalidade é posta aqui em questão, a partir do desenvolvimento de um esquema interpretativo que faz crítica aos reais limites da condicionalidade da educação quanto à sua contribuição no enfrentamento à pobreza no Brasil. A educação na execução do programa é investigada a partir da exposição teórica que questiona sua função e importância, enquanto instrumento capaz de intervir efetivamente no enfrentamento à pobreza. Entende-se que programas de transferência de renda atrelados à educação devem se fundamentar em uma proposta mais consistente sobre seu papel na contribuição do processo educativo das famílias beneficiárias do Programa Bolsa Família, portanto, sobre sua real influência no enfrentamento massivo da pobreza que acercam milhóes de brasileiros.
\end{abstract}

Palavras-chave: Bolsa Família. Educação. Pobreza.

\footnotetext{
* Mestre e Doutoranda em Serviço Social pela Pontifícia Universidade Católica de São Paulo (PUC/SP). Assistente social vinculada à Secretaria Municipal de Assistência e Desenvolvimento Social da Prefeitura São Paulo.

${ }^{* *}$ Doutora em Educação pela Universidade de São Paulo (USP). Professora na Escola de Artes, Ciências e Humanidades e dos Programas de Pós-Graduação em Educação e em Mudanças Sociais e Participaçáo Política da Universidade de São Paulo (USP).
} 


\section{Introdução}

$\mathrm{O}$ presente artigo analisa a relação de dependência entre educação e transferência de renda objetivada no Programa Bolsa Família (PBF), sobretudo entre sua proposta central de redução da pobreza e a contrapartida exigida na área da educação. A tese da eficácia de tal condicionalidade é posta aqui em questão a partir do desenvolvimento de um esquema interpretativo que analisa criticamente os reais limites da condicionalidade da educação quanto à sua contribuição no enfrentamento à pobreza no Brasil.

Sugere-se que há um reducionismo na maneira como são encaradas as atividades educacionais enquanto meta de erradicação de um problema estrutural da sociedade brasileira, a pobreza.

Observa-se que a condicionalidade da educação, assim como da saúde, é utilizada pelo PBF como um eixo estratégico no enfrentamento da pobreza no Brasil, sem que se problematize, no entanto, sua real potencialidade e eficácia na quebra do ciclo intergeracional da pobreza.

A hipótese refutada nos indica que, no máximo, o programa contribui para uma formação precária, insuficiente, parcial, produzindo uma mão de obra não qualificada, que apenas (re)produz as engrenagens do modo de produção capitalista.

O objeto de investigação neste estudo é a eficácia da condicionalidade da educaçáo no PBF e está direcionado a uma determinada realidade social. Com base nesse recorte, tem-se como ponto de partida a análise da realidade concreta, referenciada a uma formação social específica, pautada na sociedade de classes e nas relaçóes sociais oriundas do modo de produção capitalista.

Em decorrência da complexidade do tema e do necessário rigor teóricometodológico no trato dos elementos que o compóem o objeto analisado, o presente trabalho será apresentado em três sessóes distintas visando compreender a realidade social concreta a partir de uma unidade articulada.

No primeiro momento, procura-se desmistificar as interpretações restritas e economicistas relativas à pobreza no Brasil. A dimensão que compreende a configuração complexa e multicausal da pobreza no Brasil é encarada como fundamental para desvendar o significado do desenvolvimento histórico e a natureza dos programas sociais brasileiros destinados ao seu enfrentamento, como é o caso da proposta do PBF. 
No segundo momento, busca-se compreender as características históricas quanto à preocupação e postura do Estado brasileiro no trato com aqueles designados como pobres, mais especificamente através da exposição de um breve retrato histórico de alguns marcos legais considerados relevantes na contextualização do processo de discussão e implementação de Programas de Transferência de Renda (PTR) no Brasil. O recorte histórico adotado visa apontar certos períodos na discussáo sobre os PTR, principalmente aqueles atrelados à condicionalidade de educação do PBF.

No terceiro momento, é abordada a proposta da condicionalidade da educação no PBF, sua especificidade e função na execução do programa. Tais aspectos são analisados e questionados a partir da exposição de algumas interpretações teóricas que se debruçam sobre a função, a importância, os desafios e a especificidades da educação enquanto instrumento atrelado a um projeto pedagógico capaz de intervir no enfrentamento à pobreza. Ademais, o presente artigo visa ampliar as reflexóes sobre a eficácia da proposta de condicionalidade na área de educação dos programas de transferência de renda, mais especificamente do PBF, além de contribuir nas discussões acadêmicas no âmbito das temáticas que envolvem educação, serviço social, programas de transferência de renda e assistência social.

\section{A Desmistificação da Pobreza no Brasil}

Face ao objetivo geral do PBF, que tem como meta maior o enfrentamento e o alívio da condição de pobreza de milhares de famílias brasileiras, entendemos ser imprescindível traçar neste artigo uma breve reflexão crítica da realidade social, sobretudo quanto à configuração do quadro de pobreza e miserabilidade que afeta uma parcela significativa da sociedade.

A pobreza enquanto categoria sociológica suscita diversas definiçôes que, por sua vez, abrangem distintas compreensóes de suas causas. Nesse sentido, sua abordagem varia a partir da perspectiva adotada na análise do fenômeno, que muitas vezes são traduzidos em dados estatísticos que permitem o estabelecimento de uma linha oficial de pobreza e geralmente são elaboradas e utilizadas por governos para dimensionar o fenômeno e propor alternativas no campo das políticas públicas.

Atualmente, a leitura quantitativa da pobreza prevalece e sua mensuração se destaca por seu viés economicista. Desse modo, os índices monetários 
permeiam grande parte dos critérios estabelecidos na definição daquele considerado pobre.

Apesar da complexidade do fenômeno pobreza ser mais bem dimensionada a partir de suas concepçôes relativas, sua mensuração frequentemente não rompe com a visão estritamente economicista e, portanto, simplista, comumente adotada enquanto indicador e critério para sua definição. $\mathrm{Na}$ prática, a abordagem da pobreza enquanto insuficiência de renda se generalizou, como é o caso do PBF que define a pobreza exclusivamente a partir da renda per capita das famílias. A definição adotada pelo referido programa considera pobre as famílias que possuem uma renda per capita mensal de $\mathrm{R} \$ 70$ até $\mathrm{R} \$ 140,00$ e extremamente pobres aquelas com renda per capita de até $\mathrm{R} \$ 70,00$. Dessa forma, o PBF define a pobreza privilegiando a renda como critério de inclusão e elegibilidade em detrimento de outros critérios necessários para delimitar a pobreza dos cidadáos brasileiros, por isso entende-se que o programa possui uma percepçáo limitada da definiçáo do referido fenômeno social e expressa a histórica tendência das políticas sociais brasileiras, meramente compensatórias e residuais, desconsiderando a perspectiva orientada pelo entendimento de que a riqueza socialmente produzida deve, de alguma maneira, ser redistribuída aos membros da sociedade, impactando consideravelmente nos índices de desigualdade social.

Estimativas oficiais publicadas por Lavinas (2011), disponíveis no site do Ministério do Desenvolvimento Social (MDS), revelam que o país tem uma população estimada de 192 milhóes de habitantes, dos quais 18,691 milhóes são pobres (renda per capita inferior à $\mathrm{R} \$ 140,00$ ) e 10,065 são indigentes (renda per capita inferior a $\mathrm{R} \$ 70,00$ ), totalizando um valor de 28,757 milhóes de pessoas, o que equivale à $15,5 \%$ da populaçáo vivendo com menos de $\mathrm{R} \$ 140$ ao mês, portanto elegíveis ao PBF.

$\mathrm{Na}$ realidade, observa-se que os indicadores utilizados pelo Estado não mensuram a evolução da redistribuição de renda e da desigualdade no país, mascarando uma realidade perversa através dos fetiches dos números incapazes de interpretar a dinâmica e movimento da realidade social. A forma de manuseio desses dados revela um desconhecimento sistemático da realidade sob a aparência de conhecimento. Tal interpretação é típica da compreensão restrita e economicista do fenômeno da pobreza que reduz a realidade a números, num contexto em que os problemas sociais e políticos brasileiros passam a ser vistos superficialmente, fomentando o coro daqueles que pensam ser a pobreza 
superável via educação. Sobre tal aspecto, Souza (2011) afirma ser este mesmo raciocínio economicista que abstrai sistematicamente os indivíduos do seu contexto social e que, por sua vez, transforma a escola, pensada abstratamente e fora de seu contexto, em remédio para todos os males de nossa desigualdade. Nota-se que esta análise não desmerece ou desqualifica a educação, ao contrário, ela afirma que a educação é via necessária, porém, insuficiente e ineficaz quando posta de forma específica nas políticas de Estado.

A construção das ações do Estado, restrita ao viés economicista, tem como característica a desconsideração da especificidade histórica que estruturou a sociedade brasileira, sobretudo seu processo de urbanizaçáo que acelerou a concentração de renda fazendo com que, em momentos de crescimento econômico, o país não fosse capaz de erradicar sua pobreza, evidenciando a tendência estrutural para a concentraçáo de renda, inerente ao processo de industrialização ocorrido no Brasil. Desse modo, segundo Celso Furtado (1968, p. 18):

O Brasil não se desenvolveu; modernizou-se, colocou o verniz do desenvolvimento. O desenvolvimento verdadeiro só existe quando o homem é beneficiado. Grande parte da sociedade não se beneficia desse desenvolvimento. Portanto, náo existe desenvolvimento; existe, na verdade, uma modernização.

É no interior deste cenário de modernização, cujo progresso tecnológico é assimilado em sua aparência, privando à sociedade de seus frutos, que emerge a redenção da educação atrelada a programas sociais destinados ao enfrentamento da pobreza. Assim, abstraem-se sistematicamente os indivíduos do seu contexto social, transformando a escola, pensada abstratamente e fora de seu contexto, como promotora da superação dos males da desigualdade social vigente e da formação estrutural do processo de desenvolvimento do Brasil.

Entender a pobreza como fenômeno passível de ser solucionado via educação, mais especificamente pela frequência escolar, revela uma visão superficial que encobre os conflitos sociais mais profundos da realidade brasileira. Conforme mostra Souza (2011, p. 18),

Isso equivale, na verdade, a esconder e tornar invisível todos os fatores e precondiçóes sociais, emocionais, 
morais e culturais que constituem a renda diferencial, confundindo, ao fim e ao cabo, causa e efeito. Esconder os fatores não econômicos da desigualdade é, na verdade, tornar invisível as duas questôes que permitem efetivamente 'compreender' o fenômeno da desigualdade social: a sua gênese e a sua reproduçáo no tempo.

A compreensão da realidade socioeconômica que se objetiva de forma complexa é entendida como fundamental no processo reflexivo que busca abordar a situação social vigente e a constituição do fenômeno pobreza no Brasil; sua contextualização histórica é essencial para compreender o modelo adotado de política social brasileira, mais especificamente a do programa de transferência de renda, o Bolsa Família. Assim, as análises teóricas dirigidas ao $\mathrm{PBF}$ apresentam um rigor científico e metodológico mais consistente quando são interpretados para além de suas especificidades. Neste caso, considera-se que o programa passa a ser mais bem interpretado e analisado quando se tem acesso às suas determinaçōes causais, responsáveis pelas distintas manifestaçôes do fenômeno da pobreza no Brasil e quando se considera o desenvolvimento do Estado brasileiro quanto à sua capacidade protetora, orientada ao alcance universal de seus cidadãos.

\section{Os Programas de Transferência de Renda}

Os programas de transferência de renda se constituíram nos últimos anos na expressão máxima de política social em muitos países latino-americanos, e seu amplo desenvolvimento fez com que tais açôes se convertessem em estratégias centrais no enfrentamento à pobreza em muitos destes países. Nota-se que esse processo é fruto das orientaçôes político-econômicas de ajuste vigentes e impostas por organismos internacionais à regiáo, relacionadas, por exemplo, ao cumprimento dos Objetivos de Desenvolvimento do Milênio (ODM). Segundo Franco (2006), a adoção dos modelos condicionados de programas de transferências de renda contribui para alteraçóes de concepçóes de tais políticas que se convertem em única alternativa contra a pobreza.

Sob esse aspecto, uma análise introdutória sobre os programas de transferência de renda na América Latina permite identificar que esses possuem, dentre as suas semelhanças constitutivas, a exigência do cumprimento 
de contrapartidas por parte dos beneficiados, as denominadas condicionalidades, entendidas como o conjunto de açôes que os indivíduos e/ou famílias devem cumprir para que possam permanecer nos programas. (NASCIMENTO; REIS, 2009, p. 188).

Apesar dos estudos comparativos das diversas experiências nacionais latino-americanas evidenciarem características comuns no padrão de formulação e operacionalização dos modelos dos programas de transferência de renda condicionados, sua objetivação isolada nos territórios nacionais se materializa à luz das peculiaridades intrínsecas à formação econômica, social e cultural de cada sociedade.

Queremos com isso dizer que, as políticas sociais brasileiras, por estarem historicamente enraizadas em um campo social constituído por açóes de bondade, compaixão, altruísmo e caridade, configuram uma realidade social particularizada que influencia diretamente na mediação objetivada na gestão e na operacionalização do PBF. Tal hipótese é fundamentada na mediação que se estabelece na relação direta entre beneficiário e equipamentos estatais responsáveis pela execução do programa. Nesse lócus de análise, evidencia-se a existência de concepçóes conservadoras, do tipo que reforça a moral do trabalho e critica qualquer forma de garantia de renda fora da relação de trabalho (lógica mercantil capitalista), quando não é raro escutar: "Tem mais que trabalhar e procurar emprego ao invés de receber esta ajuda assistencialista do governo". Sobre isso Sposati (2010, p. 10) afirma:

Retomando a ideia de que os programas sociais são orientados por valores, moral e ética, sem dúvida, em uma sociedade de mercado e no contexto da sociedade brasileira, transferir renda fora da relação de emprego gera movimentos de resistência. Temos fortes traços conservadores e ausência de reconhecimento da cidadania a todos os brasileiros. A máxima a cada um conforme seu trabalho produtivo ou reprodutivo subordina o padrão de Proteçáo Social ao emprego e à renda e não à condição de dignidade do cidadão.

O fato de o programa ser acessado pelas famílias elegíveis através dos Centros de Referência de Assistência Social (CRAS), que também têm a 
prerrogativa de realizar o acompanhamento social das famílias beneficiárias, sobretudo daquelas que não cumprem as exigências das condicionalidades do programa, também contribui para a identificação de posturas moralistas, conservadoras e acríticas por parte dos profissionais que julgam, caso a caso, a possibilidade de reversão das sanções e desbloqueios do benefício, quando suspenso por descumprimento de condicionalidade.

A dimensão histórica da existência dos programas de transferência de renda no Brasil, até se chegar ao modelo atual do PBF, expressa o movimento das intervençôes estatais no campo social. Isso significa que sua configuração atual não é isolada de um contexto mais amplo e, ao contrário, está imbricada em um processo que favorece ora a construção, ora a desconstrução do modelo de proteção social previsto na constituição federal, pautada em princípios universais.

Um marco importante no processo de desenvolvimento histórico dos programas de transferência de renda no Brasil ocorre em 1991, quando é aprovada a Lei n. 80/91 (BRASIL, 1991), de autoria do senador da república Eduardo Suplicy, que prevê o Programa de Garantia de Renda Mínima estruturado sob o formato de imposto de renda negativo. A lei beneficiaria todos os maiores de 25 anos residentes no país que tivessem um orçamento abaixo do patamar estipulado. Neste período, surgem também as primeiras propostas que defendem a concessão do benefício de Renda Mínima articuladas com a escolarização. Tal vinculação carrega consigo o argumento de que a política social que atrela programas de transferência de renda e educação é potencializada por ser capaz de amenizar a pobreza em curto prazo e, em longo prazo, reduzir a reprodução da pobreza e seu ciclo intergeracional. Outra inovação neste campo é a introduçâo da unidade familiar no lugar do indivíduo como beneficiário do programa.

Suplicy (2010) revela que em reuniáo de economistas do Partido dos Trabalhadores (PT), em Belo Horizonte, em 1991, José Márcio Camargo, por meio de críticas à proposta de Projeto de Lei n. 80/91 (BRASIL, 1991), que prevê o Programa de Garantia de Renda Mínima, foi o precursor no debate sobre os programas de transferência de renda dirigidos às famílias que tivessem crianças em idade escolar. $\mathrm{O}$ mesmo se baseava em dois argumentos: o primeiro é que o custo da oportunidade para as famílias pobres mandarem seus filhos para a escola é muito elevado devido à diminuição da já reduzida renda familiar; o segundo se refere à deficiência da formação educacional, enquanto fator limitante do 
incremento da renda das novas geraçóes, propiciando um ciclo vicioso que faz com que a pobreza de hoje determine a pobreza do futuro. Nesse sentido, a compensação financeira para as famílias pobres permitirem a ida de seus filhos à escola seria o mecanismo de rompimento deste ciclo intergeracional da pobreza.

A partir de 1995 ocorre a expansão dos programas de transferência de renda (PTR) condicionados através de experiências implantadas em municípios, como Ribeirão Preto, Santos e Brasília. Neste período, inicia-se a formar nos meios acadêmicos e políticos a ideia que reforça a proposta da renda mínima vinculada à exigência de escolarização das crianças das famílias beneficiárias, sob o entendimento que a transmissão intergeracional da pobreza seria rompida através do aumento do capital humano entre as geraçóes, via educação.

A discussão sobre os programas de transferência de renda ganhou espaço entre 1995 e 1996 orientado por distintos posicionamentos políticos e ideológicos que se colocavam de maneira distinta, sendo mais progressista (universal e incondicional) ou conservadora (condicional e focalizada) quanto ao trato dos projetos de leis que objetivam instituir um programa de transferência de renda em âmbito nacional.

O acumulo teórico e o consenso político acerca dos PTRs condicionados na década de 1990 foi objetivado em 2001 com a criaçáo nacional do programa de transferência de renda condicionado, denominado Bolsa Escola, juntamente com outros programas sociais, são eles: Vale-gás, Cartão Alimentação e Bolsa Alimentação. Também se observa neste período a expansão do Programa de Erradicaçáo de Trabalho Infantil (PETI) (criado em 1996) e do Benefício de Prestação Continuada (BPC). Nota-se que cada programa até então estava vinculado a Ministérios diferentes, abrangendo o Ministério da Educação, Ministério da Saúde, Ministério de Minas e Energia e o Ministério Extraordinário de Segurança Alimentar e Combate à Fome.

No período de transiçáo dos governos federais (saída de Fernando Henrique Cardoso/2002 e início do governo Luiz Inácio Lula da Silva/2003) presenciam-se mudanças qualitativas e quantitativas em direção à construção de uma agenda pública comprometida com o trato social, priorizando açóes focalizadas de enfrentamento à pobreza, em especial com a política pública de transferência de renda, por meio da instituiçáo de um programa nacional massivo de transferência de renda denominado Bolsa Família. Neste momento, o enfrentamento à pobreza passa a ser prioridade nos discursos de Lula, havendo de fato uma reestruturação dos programas de transferência de renda existentes até então. 
O cenário marcado pela fragmentação dos programas existentes, com benefícios diferentes, público-alvo similares, duplicação de esforços e confusão gerencial, somados às críticas recebidas pelo programa Fome Zero ${ }^{1}$, contribuíram para o processo de unificação dos quatro programas nacionais de transferência de renda existentes até então (Bolsa Escola, Bolsa Alimentação, Vale gás e Cartão Alimentação) e a implementação do programa nacional único de transferência de renda, o Programa Bolsa Família.

A criação do "novo" programa de transferência de renda, o Bolsa Família seguiu algumas recomendaçóes orientadas a corrigir problemas identificados, oriundos da sobreposição dos programas existentes, além de transferir sua gestão do Ministério da Educação (MEC) para o Ministério do Desenvolvimento Social (MDS). No entanto, tais mudanças não alteraram o eixo das condicionalidades dos PTR, sendo que, ainda hoje, a exigência de manutenção nas escolas, por parte das crianças e adolescentes beneficiarias do PBF, parece ser socialmente significativa e expressa a originalidade da proposta como um dos eixos centrais do programa.

\section{O Programa Bolsa Família}

O programa Bolsa Família égerenciado pelo Ministério de Desenvolvimento Social e Combate à Fome e tem como principais objetivos o alívio imediato da pobreza, ruptura do ciclo intergeracional da pobreza e o desenvolvimento das famílias por meio da transferência direta de renda (BRASIL, 2004a).

O PBF se transformou rapidamente no maior programa de transferência de renda executado pela política social brasileira, tanto no âmbito de abrangência territorial quanto de recursos investidos e público-alvo atendido, tornando-se um marco na política social brasileira.

A estratégia de articular a renda proveniente do benefício monetário aos serviços no campo da educação e saúde pauta-se na crença de que os benefícios monetários operam na garantia do campo de segurança de renda, enquanto a saúde e a educação destinam-se a garantir outras seguranças sociais, também consideradas fundamentais quando se deseja combater a pobreza. Nota-se que neste ponto, aparentemente, o PBF abrange outras características que ultrapassam a restrita visão economicista da pobreza, embora considerem elegíveis somente as famílias com determinado nível de renda. No entanto, esta hipótese é refutada no presente artigo que explicita seu caráter focalista, punitivo e controlador. 
Como dito anteriormente, o PBF apresenta peculiaridades que se assentam em modelos e orientaçóes sugeridos por organismos internacionais, tais como FMI, BIRD, OIT, entre outras. Desse modo, o programa se alinha à perspectiva orientada às chamadas políticas neoliberais e focalizadas, expressas por programas que visam atender aos miseráveis dentre os pobres, além de priorizar "[...] a integralidade, a multidimensionalidade da pobreza, a centralidade na família, o ciclo de vida individual e familiar, a corresponsabilidade, gênero, etnia e raça”. (FRANCO, 2006, p. 155, tradução nossa).

$\mathrm{O} P B F$ apresenta os seguintes eixos: transferência de renda, que promove $\mathrm{o}$ alívio imediato da pobreza; as condicionalidades, que visam reforçar o acesso aos direitos sociais básicos nas áreas de Educação, Saúde e Assistência Social; e os programas complementares, que objetivam o desenvolvimento das famílias, de modo que os beneficiários consigam superar a situação de vulnerabilidade às quais estão expostos. As condicionalidades são compromissos que devem ser assumidos pelas famílias para que possam permanecer recebendo o benefício e são colocadas numa posição estratégica, sobretudo no discurso oficial do governo, na perseguiçáo dos resultados esperados pelo $\mathrm{PBF}$ no enfrentamento da pobreza no Brasil.

A proposta de transferência de renda condicionada enxerga o beneficiário como sujeito ativo e participante do processo de alcance dos objetivos esperados pelo programa. Nesse sentido, superar a condição de pobreza depende também do cumprimento das exigências de contrapartidas que, segundo sua proposta oficial, busca articular o traço meramente compensatório da transferência de renda com outros mecanismos entendidos como necessários, a médio e longo prazo, no enfrentamento da pobreza. Segundo Franco (2006), em geral, a temporalidade presumida pelos programas condicionados de renda ocorrem da seguinte maneira:

Em curto prazo, contribuindo para aliviar a pobreza, mantendo as crianças na escola e acompanhando o controle de saúde; em médio prazo, aumentar a confiança nas próprias forças dos membros da família beneficiária, que se convencem que podem sair da pobreza, mediante do treinamento que deriva do cumprimento dos compromissos assumidos ao incorporar-se ao programa. Nessa ação reiterada vão se convencendo de que não são meros entes passivos e receptores de dádivas, e sim 
autores autônomos, com capacidade para manejar seus recursos (o que se fomenta mediante a transferência de dinheiro em espécie), e que são corresponsáveis pelo êxito do programa e, em definitivo pela quebra da transmissão intergeracional da pobreza e em longo prazo, contribuindo para a formação de capital humano (FRANCO, 2006, p. 159, tradução nossa).

A lógica temporal da proposta das condicionalidades dos PTR se assenta numa visão distorcida da realidade social, cuja pobreza dos beneficiários é sempre percebida como contingente e fortuita, sendo facilmente reversível e passível de ser superada quando acompanhada do cumprimento das exigências do programa.

No caso da condicionalidade de educação do PBF, observa-se que sua vinculação revela também concepções políticas e ideológicas distintas em torno das correntes que defendem a implantação de programas de transferência de renda. Desse modo, a discussão se polariza entre transferência de renda condicionada, portanto, focalizada, e transferência de renda incondicional, ou seja, universal sem critério de inclusão e permanência, como defende a Lei no 10.835, que institui a renda básica de cidadania (BRASIL, 2004a).

A controvérsia das necessidades e impactos dos objetivos das condicionalidades no processo de enfrentamento à pobreza desvenda a presença de distintas concepçóes políticas e culturais que permeiam a proposta dos PTR condicionados, dando margem à justificativas pautadas mais na moral capitalista do que em evidências empíricas, uma vez que, segundo Britto e Soares (2010), não há análises objetivas e pesquisas que apontem a eficácia significativa do eixo da condicionalidade e justifique, portanto, sua adoçáo nos programas de transferências de renda existentes.

A existência das condicionalidades expressa um ponto polêmico no interior das discussóes sobre modelos de programas de transferência de renda, principalmente por tocar/impactar diretamente na moral do trabalho, tâo presente e (re)produzida pela sociedade capitalista vigente que explora o trabalho de maneira alienada. Nesse sentido, as condicionalidades equivalem "ao suor" do trabalho, uma simbologia necessária para garantir apoio ao programa por parte daqueles que acreditam que ninguém deveria receber uma transferência do Estado, especialmente os pobres, sem prestar alguma contrapartida direta (BRITTO; SOARES, 2010). 
Assim, os críticos da proposta de incondicionalidade dos programas de transferência de renda alegam que sem a verificação das condicionalidades o mesmo se resume a "dar o peixe, sem ensinar a pescar", na medida em que, como aponta Britto e Soares (2010), deixam de proporcionar incentivos para que os beneficiários invistam na educação e na saúde, relegando, dessa maneira, a segundo plano, os objetivos de longo prazo desse tipo de iniciativa.

$\mathrm{O}$ atual estágio de discussão sobre programas de transferência de renda no Brasil, principalmente nos meios políticos, não aponta questionamentos quanto ao quesito da condicionalidade, ou seja, o princípio constitucional da universalidade da política social não parece estar em pauta quando o assunto é o enfrentamento da pobreza.

A ênfase na noção de condicionalidades presentes nos modelos de programas de transferência de renda expressa a discussão acerca do princípio universal e incondicional dos programas versus princípio focalizado e condicionado, portanto, estabelecer compromissos como contrapartida para o recebimento do benefício monetário suscita e esbarra em contrastes significativos que diferenciam modelos possíveis de Proteção Social.

No programa Bolsa Família a condicionalidade referente à educação exige que as famílias matriculem as crianças e adolescentes de 6 a 17 anos na escola, garantindo a frequência mínima mensal de $85 \%$ das crianças de 6 a 15 anos e $75 \%$ dos adolescentes de 16 a 17 anos; além disso, as mesmas devem informar à escola quando o aluno necessitar faltar, explicar o motivo e informar ao gestor do PBF sempre que algum aluno mudar de escola, para que os técnicos da prefeitura possam continuar acompanhando a frequência escolar desses alunos.

As famílias que descumprem tais compromissos estão sujeitas as sançôes gradativas previstas em lei (BRASIL, 2004b), que vão desde a notificação, passando pela suspensão do benefício, podendo chegar ao cancelamento do mesmo, caso o descumprimento aconteça por cinco períodos consecutivos.

O programa impóe o acompanhamento para aquelas famílias que apresentam frequência escolar inferior ao exigido, por meio de trabalhos socioeducativos e encontros sistemáticos com as famílias, geralmente promovidos no âmbito da política pública de Assistência Social.

O programa ao estabelecer as condicionalidades na área da educação atribui à frequência por parte das crianças e adolescentes beneficiárias na escola um propósito e intencionalidade direcionados ao rompimento do chamado 
ciclo intergeracional da pobreza. Dessa maneira, a escola é projetada como um espaço que ultrapassa os limites físicos e geográficos e que, por isso, possui uma finalidade educativa e um projeto pedagógico capaz de alcançar a inclusão social e autonomia do cidadáo, contribuindo para a superação da condiçấo que o faz elegível ao programa.

Nesse sentido, o PBF assume a tese que associa a incidência da pobreza aos níveis baixos de escolaridades, desconsiderando a complexidade do fenômeno da pobreza quanto às suas reais causas. Além disso, o programa visa reduzir a concepção crítica acerca do problema ao sugerir uma relação recíproca e proporcional entre pobreza e frequência escolar, ou seja, por esse raciocínio a situação de pobreza da geração futura passa a ser uma questão meritocrática, uma vez que permanece na condição de pobre somente aquele que não faz a sua parte, ou não cumpre as exigências das condicionalidades dos programas de transferência de renda no presente.

\section{Educação como instrumento de combate à pobreza}

A problematização do papel da educação no combate à pobreza, vinculada à análise da condicionalidade no PBF, é abordada neste artigo a partir da mediaçáo de uma abordagem teórica que considera a relaçáo existente entre educação e sociedade em suas dimensóes macro e micro. Para tanto, faz-se necessário reconhecer na educação sua dimensão histórica, inserida num contexto político e social amplo e complexo que envolve o movimento de expansão do modo de produção capitalista. Entende-se que este, por sua vez, determina a existência de fatores condicionantes que incidem diretamente na análise do retrato da educação e do sentido da escola na sociedade brasileira.

Os fatores condicionantes que incidem sobre a educação são apontados por Cury (2002) e Souza Jr. (2010), sendo eles: matéria socioeconômica, conceito próprio de educação, a ação do Estado e suas obrigaçóes na oferta da educação, a exclusão histórica decorrente da extrema desigualdade socioeconômica, a mundialização do capital, a financeirização da economia, o crescimento do fenômeno do desemprego estrutural ou crônico, a consequente criaçáo da chamada população supérflua, a hegemonia ideológica e política conservadora, a crise do trabalho assalariado e a dita crise dos Estados-Nacionais.

Analisar o papel da educação nesse contexto implica reconhecer a influência de seus condicionantes, sem perder de vista a dimensão de suas 
especificidades pedagógicas. No entanto, no Brasil existe uma histórica tendência em desconsiderar a perspectiva pedagógica da educação, sobretudo quando se trata de discussóes acerca das práticas educativas ofertadas no âmbito da política educacional do país, deixando as políticas educativas em detrimento às políticas educacionais. Nesse sentido, Libâneo (2011) explicita que as políticas educacionais estão centradas no seu aspecto gerencial (macro), enquanto as políticas educativas estão centradas no aspecto pedagógico (micro) da educação. A partir desta relação, percebe-se a incidência da desatençáo com os aspectos pedagógico-didáticos por onde, efetivamente, seriam asseguradas as condiçóes de qualidade de ensino, no que se refere ao objeto deste estudo. Entende-se, no entanto, que a relaçáo entre essas distintas dimensões das políticas aponta que a primeira, a política educacional, deve submeter-se à segunda, a política educativa, sendo a inversão dessa lógica um dos possíveis responsáveis pelo fracasso da escola e da educaçáo no Brasil.

$\mathrm{O} \mathrm{PBF}$ se alinha à perspectiva que não considera as especificidades das políticas educativas, uma vez que não existe uma preocupação centrada na análise pedagógica que especifique a educação em sua dimensão pedagógicodidática, sobretudo no âmbito da condicionalidade do programa. Nesse sentido, a condicionalidade da educação no programa, ao ignorar esse princípio básico, acaba por substituir a função pedagógica da educação pela função social.

$\mathrm{Na}$ análise da educação, o discernimento entre a distinção dos seus focos pedagógicos e sociológicos passa necessariamente pelo entendimento crítico e histórico da função da educação na transformação da sociedade e dos próprios sujeitos. Sobre tal aspecto, Bernardes (2010) considera que, nas práticas educativas que objetivam a transformação da formação humana orientada por princípios emancipadores, é necessária a superação da concepção de educação que visa à formação de mão de obra destinada a ocupar funções precárias na divisão do trabalho do sistema capitalista vigente.

No Brasil contemporâneo a vinculação existente entre educação e sociedade ocorre de forma a reproduzir e perpetuar a estrutura desigual da nossa sociedade. Diante desse cenário, a expectativa da educaçáo condizente com a perspectiva marxista é, em nosso entendimento, a que possibilita orientaçóes concretas quando se objetiva criar condiçóes para a transformação dos sujeitos e da própria sociedade. Entende-se, portanto, que a educação organizada a partir de tais princípios possa contribuir no combate à pobreza, uma vez que cria possibilidades efetivas na apropriação da produçáo material e imaterial 
produzida pelo conjunto dos homens. Sobre tais orientações, Bernardes (2010, p. 294) afirma que:

[...] no campo da educação tais aspectos relacionam-se ao fato de que o conhecimento produzido historicamente não é mediado nas escolas para que os sujeitos possam tornar-se herdeiros de uma cultura universal; o significado social da educaçáo não corresponde ao sentido pessoal que a educação passa a ter pelos sujeitos quando a finalidade da própria educação escolar é negada pelas açóes pedagógicas instituídas na agencia oficial instituída historicamente - a escola - em decorrência das políticas educacionais instituídas nas sociedades de classe. [Entende-se que] [...] as condiçóes instituídas na educação escolar precisam ser superadas para que cumpra a finalidade de educação - a promoção do humano nos sujeitos individuais por meio da medicação do conhecimento elaborado historicamente.

Trata-se, portanto, de objetivar a educação como mediadora dos processos de formação humana pautadas na análise crítica da realidade social existente, mediante sua configuração na forma de instrumentos de lutas e formas de sociabilidade superiores, livres e emancipatórias. A partir deste entendimento, questiona-se o real papel da educação inserida na sociedade contemporânea e por ela condicionada, bem como suas possibilidades concretas criadas pelas atuais circunstâncias econômica, social e cultural, mediadas pela política de Estado no campo da educaçáo, em superar o dramático cenário nacional de pobreza e desigualdade social.

Verifica-se, no cotidiano escolar, que a escola não consegue realizar sua promessa inclusiva no contexto geral da sociedade. Neste aspecto, questiona-se em relação ao contingente dos beneficiários do $\mathrm{PBF}$, que a própria dinâmica nuclear da sociedade atual considera supérfluo (os chamados excluídos); que tipo de educação se adequará à condição tão rebaixada de trabalho e de cidadania?

Compreender a escola como instituição determinada histórica e socialmente, portanto, instrumento de (re)produção das relaçóes sociais oriundas do modelo de produção capitalistas, evidencia o caráter intrinsecamente contraditório dos modelos de PTR condicionados, que exige o acesso e a permanência por parte dos beneficiários em escolas historicamente marcadas 
pela (re)produção das relações de produção baseadas na dominação e exploração, por sua vez responsáveis pela situação de pobreza vivenciada por milhóes de brasileiros.

Conforme demonstra a pesquisa publicada pelo Centro de Estudos e Pesquisas em Educação, Cultura e Ação Comunitária (Cenpec) (ÉRNICA; BATISTA, 2011), o modelo institucional que orienta as escolas não está preparado para se relacionar com territórios de alta vulnerabilidade social escolar, o que as tornam incapazes de se estabelecerem enquanto instituição criadora de possibilidades concretas para a superação do problema da marginalidade e da pobreza. Ainda, segundo a pesquisa, "tudo indica que o colapso é de um modelo institucional” (ÉRNICA; BATISTA, 2011, p. 12).

A princípio, uma preocupação real da problemática da educação, atuante no enfrentamento à pobreza, entende que a educação formal é apenas uma estrutura auxiliar no processo formativo do ser social, ou seja, sua existência é uma possibilidade e náo uma certeza, quando comprometida com o caráter de enfrentamento da pobreza. Sendo assim, verifica-se que a educação e suas condiçóes institucionais, na forma como estão estruturadas, pouco podem contribuir para o propósito do PBF, tampouco com a formação do homem na sua integralidade.

A importância dos aspectos pedagógico e didático, que implicam em atividades pedagógicas conscientes e devidamente organizadas visando ao fim da educação (BERNARDES, 2010), parecem não ser consideradas quando se trata da condicionalidade da educação pelo PBF. Evidencia-se nesta política de Estado, que o objetivo de ensino e de aprendizagem, enquanto promotores do homem como sujeitos ativos na sociedade, não é prioridade. Tal fato revela a sobreposição das políticas educacionais em relação às políticas educativas, conforme exposto anteriormente.

Ademais, parece-nos relevante pensar sobre a possibilidade de se estar na escola sem, no entanto, vivenciar a escola, sua dinâmica, rotinas e afazeres. $\mathrm{O}$ $\mathrm{PBF}$ ao reduzir a importância da educação na exigência da frequência escolar se posiciona em direção ao "estar na escola", em detrimento ao "viver a escola". Além do mais, contribui na incorporação do estigma do negligente por parte de famílias que, sem possuir uma ligação objetiva com o conhecimento, são obrigadas a priorizar tal condição no desenvolvimento e formação de seus dependentes/filhos; é esta imagem redutora e desvalorizada que o Estado e a sociedade conferem às famílias beneficiarias designadas como descumpridoras 
de um compromisso assumido perante o governo e por isso passíveis a sanções que podem chegar ao cancelamento da renda transferida. Desse modo, conforme aponta Freitas (2011), a prática comum passa a punir e castigar as famílias beneficiárias que apresentam esse tipo de comportamento, encarado-as como consequência de uma escolha racional de cada uma, e não como efeito de uma condição de vida que não oferece as condiçốes sociais objetivas para o sucesso da vida escolar.

A proposição aqui defendida é a de que o não cumprimento da frequência escolar, minimamente exigida pelo $\mathrm{PBF}$, não está relacionada com uma deficiência ou problema específico de cada família, por isso o caráter punitivo do descumprimento da condicionalidade não pode estar direcionado exclusivamente à família. Por este raciocínio, questiona-se quem e quais as punições dirigidas ao Estado, que não cumpriu com seus princípios básicos, de minimamente assegurar a tais famílias as condiçóes objetivas de acessarem padrōes básicos e dignos de existência e reprodução social.

A realidade social indica que no Brasil o poder que se pretende ter a exigência de uma frequência mínima vinculada à transferência de renda e associada à inclusão social, construção de conhecimento, formação humana e proteçáo social é muito menor do que oficialmente declara ter a proposta de condicionalidade de educação do PBF.

A vinculação entre transferência de renda e frequência escolar reflete a concepção simplista de que as políticas públicas envolvidas no PBF possuem da problemática da pobreza e da educação no país, bem como do entendimento limitado da intersetorialidade postas nas políticas sociais envolvidas no programa (Saúde, Educação e Assistência Social).

Outro ponto necessário ao debate aqui proposto refere-se ao questionamento do patamar de institucionalização da educação na sociedade brasileira; isto porque, apesar dos discursos e metas oficiais do Estado advogarem a favor do direito de todos à educação pública, gratuita e de qualidade, não foi nesse sentido que se direcionaram as açóes do Estado durante todo o período histórico. Sendo assim, cabe indagar que educação é essa que o PBF propóe sem que o Brasil ao menos tenha definido uma pauta mínima sobre política educativa e educação pública. Por ora, o que acontece é uma ênfase dada na aprendizagem de 7 a 16 anos, em detrimento de outras etapas igualmente importantes na formação educacional, como é o caso da educação infantil e ensino médio, que não são exigidos como condicionalidades do PBF. Essa 
constatação nos permite apontar a fragilidade e a contraditória proposta de condicionalidade de educação do PBF, que sequer menciona a necessidade e a importância do cumprimento das três etapas da educação (educação infantil, ensino fundamental e ensino médio), consideradas pela própria Lei de Diretrizes e Bases (LDB), como básicas, elementares e sequenciais.

Desse modo, o PBF não exige sequer o mínimo considerado indispensável para o exercício da cidadania e progressão no trabalho, indicando um contrassenso na vinculação estabelecida entre frequência escolar e transferência de renda, sobretudo quando tal vinculação se materializa por uma relação condicionada, sujeita a sançóes quando não cumpridas.

Entende-se que atribuir à educação uma função capaz de suprir desvantagens/distorçóes sociais por meio de uma proposta pedagógica que conduz à mobilidade social, expresso aqui pelo fato do beneficiário do programa frequentar a escola como condição necessária à superação da sua condição de pobre ou extremamente pobre, refere-se ao que Saviani (2009) designa por educação compensatória. Nesses casos, tais programas acabam colocando sob a responsabilidade da educação uma série de problemas que não são especificamente educacionais, o que significa a persistência da crença ingênua no poder redentor da educação em relação à sociedade, atribuindo à educação um conjunto de papéis que, no limite, abarcam as diferentes modalidades de política social.

Tal concepção que atribui uma determinada função à escola e às práticas educativas, no entanto, não só as simplificam e as desqualificam como contribuem para uma visão não critica da problemática educacional e da questão social brasileira que são tratadas de maneira sobrepostas pelo PBF. Ademais, assim como pontua Cury (2002, p. 169), não se deve exigir da escola o que não é dela, sendo necessária a superação da sua "concepção salvadora, redentora e equalizadora”.

Por ora, a relação estabelecida entre condicionalidade de educação e transferência de renda se materializa de forma pouco apurada, ou seja, a finalidade de sua existência não se efetiva e a expectativa de uma formação comprometida com o enfretamento à pobreza se traduz numa mera abstração e incoerência. Conforme afirma Libâneo (2011, p. 86): "São práticas aparentemente progressistas, de falso pioneirismo, e até revestidas de argumentos psicológicos humanistas, mas não vão fundo na solução dos problemas propostos".

Ademais, a gestão das condicionalidades do PBF ainda não se consolidou a 
ponto de justificar sua existência; ao contrário, os resultados esperados parecem estar distantes de se materializarem na sociedade brasileira.

\section{Considerações finais}

Entendemos, em decorrência do estudo aqui apresentado, que o PBF compreende um propósito específico à educação ao mencioná-la na execução do programa. A hipótese confirmada revela que atribuir uma determinada função à política educacional, mais especificamente à educação básica como instrumento de enfrentamento à pobreza, não apenas simplifica e desqualifica a especificidade pedagógica da educação, como contribui para uma visão reduzida, mascarada e não crítica do problema relativo ao enfrentamento da pobreza no Brasil, revelando uma visão superficial que encobre os conflitos sociais estruturais mais profundos da realidade brasileira.

Partindo do pressuposto que a principal determinaçáo causal da pobreza no Brasil refere-se à persistência das grandes desigualdades que caracterizam o país, foi possível perceber as reais limitaçóes da intencionalidade da condicionalidade de educaçáa do PBF, sobretudo, quando o assunto é o enfrentamento à pobreza. Neste caso, a meta principal do programa se faz, por demais, ousada e limitada.

Verifica-se que a obrigatoriedade da frequência escolar exigida pelo PBF, ao que tange seu objetivo de enfrentamento à pobreza, é ineficaz e ineficiente; em última análise a essência do PBF parece desconsiderar algumas pré-condiçôes sociais que são anteriores à socialização promovida pela escola, porém não menos importante, uma vez que são tais condições que determinam a relação estabelecida entre as famílias beneficiárias e o ambiente escolar. A proposta da condicionalidade de educação, tal como está estruturada no PBF, indica haver uma dificuldade por parte do Estado em considerar e analisar as causas que determinam o náo cumprimento da condicionalidade da educaçáo das famílias beneficiárias do programa. A operacionalização do programa desconsidera a realidade das escolas e a realidade social na quais crianças e adolescentes beneficiários do PBF estão inseridas, cuja própria dinâmica das relaçôes sociais não colabora no cumprimento da condicionalidade.

Entendemos que a coerência e eficácia da proposta dos programas de transferência de renda condicionados à educação apenas se torna minimamente pertinente quando se considera o processo de concentração de renda e da 
desigualdade socioeconômica peculiar à sociedade brasileira, como fator necessário a ser abordado quando a pretensão é a erradicação da miséria e redução da pobreza no Brasil. Nesse caso, conforme aborda Sposati (2010), é preciso promover, por meio de açôes públicas, transferência de renda dos mais ricos para os mais pobres, como um jogo de soma zero e superar a visão focal e condicionada dos programas de transferência de renda, tradicionalmente promovidos pela política social brasileira, que caminham em direção contraria à universalização e ampliação da proteção social.

O real enfrentamento da pobreza no Brasil depende de uma atenção por parte do Estado realmente comprometido com seus fatores causais, dialogando com a totalidade dos direitos sociais e estabelecendo uma comunicação com as políticas econômicas, agrárias, tributárias, habitacionais, inflacionárias, culturais, entre outras, ampliando sua base de financiamento e eliminando mecanismos estatais de concentração de renda.

Além disso, a análise da proposta da condicionalidade de educação do $\mathrm{PBF}$ nos permite identificar que essa modalidade de programas de transferência de renda faz coro às concepçóes da ala mais conservadora da sociedade, uma vez que são valorizadas como mecanismo de triagem, elegendo entre as famílias beneficiárias, consideradas pobres e extremamente pobres, aquelas merecedoras ou não do benefício monetário.

Nessa lógica meritocrática, evidencia-se a ideia de merecimento que permeia a vertente que náo entende ou aceita a legitimidade da proposta de transferência de renda incondicional. $\mathrm{O}$ mérito, dessa forma, é identificado enquanto elemento influenciador dos modelos de programas de transferência de renda condicionados, ou seja, o modo operante dessa política social é diretamente infiltrado por visóes acríticas, ahistóricas e por isso também moralizantes, uma vez que as famílias que descumprem as condicionalidades, muitas vezes, são tachadas como não merecedoras do benefício monetário e negligentes para com a criação e desenvolvimento dos filhos em idade escolar.

Nesse aspecto, a crítica se direciona à gestâo das condicionalidades do $\mathrm{PBF}$, que adota práticas punitivas ao sancionar a família que não cumpre a condicionalidade, encarando tal comportamento como consequência de uma escolha racional individual e não como efeito de uma condição de vida que não oferece as condiçóes sociais objetivas para o sucesso da vida escolar (SOUZA, 2011). Desse modo, pode-se afirmar que a superação das condicionalidades do PBF em direção à universalização das políticas sociais apenas se materializará quando 
houver uma mudança paradigmática dos valores morais da sociedade brasileira.

Segundo Sposati (2009), a superação do consenso conservador requer questionar qual padrão de segurança social e de relaçóes civilizatórias que a sociedade brasileira irá operar na busca da igualdade, da equidade e da justiça social entre os seus semelhantes; contudo, é preciso combater a cultura e o consenso brasileiro, marcados por uma relação parasitária em relação aos modelos de políticas sociais conservadoras e restritivas, reforçando seu caráter seletivo, além de focar o caráter do beneficiário e não sua necessidade, o pobre e não a pobreza.

É no interior desta cultura política conservadora que a sociedade passa a dar um peso maior a que de fato possui a frequência escolar, configurando a educação como elemento prioritário quando o assunto é o enfrentamento da pobreza no Brasil. Tal consenso aposta na educação, enquanto fórmula messiânica, e está amparada pela crença comum dos brasileiros, marcada pela forte resistência às políticas sociais, universais, incondicionais e redistributivas. No interior desta lógica, a instituição escolar cria oportunidades de mobilidade social por si só, sem envolver a redistribuição de renda e a riqueza socialmente produzida no país.

No interior dessa compreensão, a proposta de transferência condicionada do PBF se sustenta no pressuposto cujo montante transferido deve ser o mínimo possível para não desestimular o indivíduo na busca, a qualquer custo, da sua inserção no mercado de trabalho (não vamos aqui entrar no mérito da questão da precariedade e do subemprego presentes na realidade social).

Esta afirmação, ponto de polêmica no interior da discussão sobre programas de transferência de renda, contém a ideia de que, sobretudo no Brasil, as políticas sociais sáo orientadas por valores morais, ora mais conservadores, ora mais progressistas, prevalecendo entre essas as concepçôes mais conservadoras, portanto, mais restritivas e focalizadas de programas sociais, como é o caso do PBF.

É em meio esta perspectiva ideológica, cultural e econômica, que permeia a sociabilidade das relaçốes sociais brasileiras, que a problemática estabelecida entre educação e pobreza, frente à condicionalidade do PBF no campo da educação, se materializa e se faz presente.

Entendemos que as concepçóes e práticas educativas, bem como a institucionalização escolar, objetivam-se no conjunto das relações sociais e estâo imbricadas na realidade social, que, por sua vez, orienta a formatação da 
estrutura dos programas de transferência de renda, determinando sua faceta condicionada ou incondicional.

Desse modo, as propostas de programas de transferência de renda condicionados, que realmente carregam a intencionalidade de impactar significativamente no enfrentamento da pobreza no Brasil, devem primeiramente fazer parte do escopo de uma reflexão mais ampla e crítica sobre a realidade social brasileira, considerando seu metabolismo social de maneira radical e levando em consideração as questóes postas que configuram a gênese do quadro de pobreza e da desigualdade social no Brasil. Sobre isso, localizamos a gênese da questão no sistema econômico vigente, que historicamente determina as possibilidades de existência dos sujeitos na sociedade brasileira e não permite a exclusão da pobreza.

Com certeza, os resultados positivos do PBF tendem a ampliar sua aceitação e reduzir sua resistência. No entanto, esse imaginário criado induz a sociedade a crer numa utópica redistribuição de renda que, na realidade, não passa de uma falácia diante dos severos índices de desigualdade social apresentados no Brasil. Nesse contexto, torna-se fundamental e necessário o olhar vigilante, crítico e questionador para identificar os limites e apontar os desafios do PBF na tarefa de enfrentamento da pobreza no Brasil.

Filomeno (2011) destaca como um dos desafios postos aos PTR, a contradição de um Estado que promove a transferência de renda para os pobres, mas, ao mesmo tempo, implementa um sistema tributário regressivo e gasta uma enorme parte de sua receita em pagamentos de juros que são apropriados por uma pequena parte da sociedade, constituída pela classe de detentores de capital circulante. Desse modo, sustenta que a nossa custosa dívida pública interna e o nosso regressivo sistema tributário são mecanismos massivos de concentração de renda, onde se se institucionaliza a desigualdade social, em contradição frontal com as políticas sociais implantadas no Brasil contemporâneo, tal como propõe o $\mathrm{PBF}$.

Diante desse processo de análise, concluímos que a educação no trato dos problemas sociais é sempre uma possibilidade e não uma certeza. Além do mais, sua existência atrelada às condicionalidades do PBF apenas se torna minimamente plausível quando esta passa a ser encarada e comprometida com a especificidade e a seriedade que o fenômeno educativo/pedagógico e social requer no interior da complexa realidade social brasileira. 
A escola e as políticas educacionais precisam ser encaradas com mais atenção, uma vez que, não é qualquer escola que faz a diferença no processo de formação cidadã do aluno. Acreditamos que a educação comprometida com a inclusão e proteção social só pode se objetivar quando a sociedade criada pelos Homens for transformada pelos próprios Homens no exercício de superação da sua própria criação.

Com isso, afirmamos que a proposta condicionada do PBF pode ser uma tentativa, no entanto, é contraditória em si mesma, pois não está inserida dentro de condições minimamente necessárias à transformação econômica, social e política da realidade social brasileira.

A vinculação existente entre programas de transferência de renda e a condicionalidade de educação deve ser encarada com criticidade; apenas dessa maneira é possível identificar sua relativa importância no trato da questão social brasileira. Nesse contexto, Souza (2011, p. 17) alerta que:

$\mathrm{Na}$ realidade a escola, pensada isoladamente e em abstrato, vai apenas legitimar, com o "carimbo do Estado" e anuência de toda a sociedade, todo o processo social opaco de produçáo de indivíduos "nascidos para o sucesso", de um lado, e dos indivíduos "nascidos pelo fracasso", de outro. Afinal, o processo de competição social náo começa na escola, como pensa o economicismo, mas já está, em grande parte, prédecidido na socialização familiar pré-escolar produzida por 'culturas de classes' distintas.

É nítido que a participação da educação é importante, porém, não é suficiente para impactar na realidade brasileira marcada por uma estrutura extremamente desigual, responsável por estatísticas que envergonham a nação quanto ao número inaceitável de brasileiros pobres.

Por ora, a escola é somente uma agência, cujo sentido está fragmentado de seu significado histórico, isso porque compreendemos que a instituiçấo escolar é produto do processo de alienação intrínseca à sociedade capitalista e, no atual estágio de desenvolvimento, entendê-la como mecanismo de transformaçáo, não passa de uma suposição idealista e pouco efetiva no enfrentamento à pobreza.

A escola e a educação precisam estar inseridas num momento mais amplo de transformação, e é somente desta maneira que as atribuiçóes específicas que 
são próprias ao conceito de educação e as condições específicas responsáveis pela estrutura desigual da sociedade brasileira serão consideradas. Ao contrário, o que se observa atualmente é a perversidade do papel do Estado que consiste na não garantia de condiçôes (macro e micro) para a permanência desses jovens na escola.

A omissão do Estado (políticas educacionais) somada à precariedade das açôes educativas, infraestrutura das escolas e especificidade da condição social (pobreza e extrema pobreza), que caracteriza as famílias beneficiárias do PBF, resulta numa situação catastrófica. Esta combinação é um fracasso quando associada ao objetivo de enfrentamento da pobreza e sua integração dissociada desses fatores é uma falácia, uma alternativa conservadora, acrítica, não reflexiva da dinâmica da realidade social brasileira.

Diante do observado, é fundamental reestruturar a proposta do PBF, a fim de que este considere a especificidade da contribuição pedagógica da educação; ao contrário, sua intencionalidade, que justifica a vinculação entre a exigência de um mínimo de frequência escolar ao recebimento do benefício, será dissolvida, e em nada contribuirá para a alteração das condiçóes de vida da população beneficiária do programa.

\section{Notas}

${ }^{1} \mathrm{O}$ Fome Zero fazia referência a um conjunto de políticas sociais impulsionadas pelo governo federal e tinha por princípios a transversalidade e intersetorialidade das ações estatais nas três esferas de governo, no desenvolvimento de açóes conjuntas entre o Estado e a sociedade e na superação das desigualdades econômicas, sociais, de gênero e raça.

\section{REFERÊNCIAS}

BERNARDES, Maria Eliza Mattosinho. A construção do pensamento na atividade prática: implicações no processo pedagógico. In: REUNIÃO ANUAL DA ASSOCIAÇÃO NACIONAL DE PÓS-GRADUAÇÃO E PESQUISA EM EDUCAÇÃO, 33., 2010. Caxambu. Anais...

Caxambu, MG: ANPED, 2010. Disponível em: <http://www.anped.org. br/33encontro/app/webroot/files/file/Trabalhos\%20em\%20PDF/GT206166--Int.pdf>. Acesso em: 12 jun. 2011. 
BRASIL. Senado Federal. Projeto de Lei da Câmara no 2561, de 1992 (PLS 80/91). Institui o Programa de Garantia de Renda Mínima - PGRM e dá outras providências. Brasília, 16 abr. 1991. Disponível em: <http://www.senado.gov.br/ senadores/Senador/esuplicy/Programa/projeto_lei.asp>. Acesso em: 15 jul. 2011.

Lei no 10.835 , de 8 de janeiro de 2004. Institui a renda básica de cidadania e dá outras providencias. Diário Oficial da União, Brasília, DF, 9 jan. 2004. Disponível em: <http://www.planalto.gov.br/ccivil_03/_ato20042006/2004/lei/l10.835.htm>. Acesso em: 20 set. 2011.

Lei no 10.836, de 9 de Janeiro de 2004. Cria o Programa Bolsa Família e dá outras providências. Diário Oficial da União, Brasília, DF, 12 de jan. 2004b. Disponível em: <http://www.planalto.gov.br/ccivil_03/_ ato2004-2006/2004/lei/110.836.htm>. Acesso em: 20 set. 2011.

BRITTO, Tatiana Feitosa; SOARES, Fábio Veras. Bolsa Família e Renda Básica de Cidadania: um passo em falso? Brasília, DF: Senado Federal, ago. 2010. Disponível em: <http://www2.senado.gov.br/bdsf/item/id/188905>. Acesso em: 4 out. 2010.

CURY, Carlos Roberto Jamil. A Educação Básica no Brasil. Educação \& Sociedade, Campinas, SP, v. 23, n. 80, p. 168-200, set. 2002. Disponível em: <http://www.scielo.br/scielo.php?script=sci_arttext\&pid=S010173302002008000010\&lng=en\&nrm=iso >. Acesso em: 1 out. 2011.

ÉRNICA; Maurício; BATISTA, Antonio A. Gomes. Educação em territórios de alta vulnerabilidade social na metrópole: um caso na periferia de São Paulo. Centro de Estudos e Pesquisas em Educação, Cultura e Ação Comunitária, São Paulo, n. 3, nov. 2011. (Relatório de Pesquisa).

FILOMENO, Felipe Amin. Brasil Sem Miséria: desafios e contradiçôes. Outras palavras: comunicação compartilhada e pós-capitalismo, São Paulo, 27 jun. 2011. Disponível em: <http://www.outraspalavras.net/2011/06/27/ brasil-sem-miseria-desafios-e-contradicoes/>. Acesso em: 5 abr. 2012.

FURTADO, Celso. Um projeto para o Brasil. Rio de Janeiro: Saga, 1968.

FRANCO, Rolando. Modelos de política social en América Latina en el último cuarto de siglo. In: FRANCO, Rolando; LANZARO, Jorge (Coord.). Politica y politicas públicas em los processos de reforma de América Latina. Buenos Aires: Miño y Dávila, 2006. p.147-168. 
FREITAS, Lorena. A instituição do fracasso: a educação da ralé. In: SOUZA, Jessé. A ralé brasileira: quem é e como vive. Belo horizonte: Editora da UFMG, 2009. p. 281-304.

LAVINAS, Lena. Status e direitos para galvanizar oportunidades: desafios do combate à miséria frente às incertezas da conjuntura econômica. In: SEMINÁRIO INTERNACIONAL PROTEÇÃO SOCIAL E CIDADANIA, 2011, Brasília. Anais... Brasília, DF: MDS, 2011. Disponível em: <http://www.mds.gov.br/saladeimprensa/eventos/avaliacao-e-gestaoda-informacao/seminario-internacional-sobre-protecao-social-e-cidadania/ sobre-o-evento/lena-lavinas.pdf/view?searchterm=lena\%20lavinas $>$. Acesso em: out. 2011.

LIBÂNEO, José Carlos. Escola pública brasileira, um sonho frustrado: falharam as escolas ou as políticas educacionais? In: LIBÂNEO, José Carlos. Didática e escola em uma sociedade complexa. Goiás: CEPED, 2011.

NASCIMENTO, Ana Fátima de; REIS, Carlos Nelson dos. Os Programas de Transferência de Renda na América Latina: especificidades de uma realidade que se mantém. Revista Políticas Públicas, São Luis, MA, v. 13, n. 2, p. 183-193, jul./dez. 2009.

SAVIANI, Dermeval. Escola e democracia: teorias da educação, curvatura da vara, onze teses sobre a educação política. 41. ed. Campinas, SP: Autores Associados, 2009.

SOUZA JR., Justino. Marx e a crítica da educação: da expansão liberaldemocrática à crise regressivo-destrutiva do capital. Aparecida, SP: Ideias \& Letras, 2010.

SPOSATI, Aldaíza. Bolsa família: um programa com futuros. In: CASTRO, Jorge Abrão; MODESTO, Lúcia (Org.). Bolsa Família 2003/2010: avanços e desafios. Brasília, DF: IPEA, 2010. 2 v.

SUPLICY, Eduardo Matarazzo. Renda de cidadania: a saída é pela porta. 6 . ed. São Paulo: Cortez, 2010. 


\section{La condicionalidad de la educación de los programas de transferencia de renta: un análisis crítica del programa Bolsa Família}

\section{Resumen}

El presente artículo analiza la relación de dependencia entre la educación y la transferencia de renta objetivada en el Programa Bolsa Familia (PBF), en Brasil, sobre todo entre su propuesta central de reducción de la pobreza y la contrapartida exigida en el área de la educación. La tesis de la eficacia de tal condicionalidad es puesta aquí en cuestión, a partir del desarrollo de un esquema interpretativo que analiza de modo crítico los reales límites de la condicionalidad de la educación en cuanto su contribución en el enfrentamiento a la pobreza en el Brasil. La educación, a partir de la ejecución del programa, es analizada a partir de la exposición teórica que cuestiona su función e importancia en cuanto instrumento capaz de intervenir efectivamente en el enfrentamiento a la pobreza. Se entiende que programas de transferencia de renta asociados a la educación deben fundamentarse en una propuesta más consistente acerca de su papel en la contribución del proceso educativo de las familias beneficiarias del PBF, por lo tanto, acerca de su real influencia en el enfrentamiento masivo de la pobreza que rodea millones de brasileros.

Palabras claves: Bolsa Familia. Educación. Pobreza.

\section{The conditionality of the education programs of income tranfer: a critical analysis of the program Bolsa Família}

\begin{abstract}
This paper analyzes the interdependence between education and income transference which is the aim of Bolsa Família Program (PBF) principally its main proposal that is poverty reduction and the counterpart required in the education area. The thesis of the effectiveness of such a compliance is discussed in this paper, from the development of an interpretative scheme which critically analyzes the real limits of conditionality of education due to its contribution in fighting against poverty in Brazil. Education in implementing the program is analyzed from a theoretical exposition questioning their role and importance as an instrument capable of intervening effectively in fighting poverty. It is understood that income transfer programs linked to education should be based on a proposal more consistent about their role in the educational process of PBF beneficiary families, therefore, about their real influence in the face of massive poverty that surrounds millions of Brazilians.
\end{abstract}

Keywords: Bolsa Família. Education. Poverty. 
Bruna Cristina Neves Carnelossi

E-mail: bru-carnelossi@uol.com.br

Maria Eliza Mattosinho Bernardes

E-mail: memberna@usp.br

Recebido em: 29/2/2013

Versáo final recebida em:

Aprovado em: 15/8/2013 